\title{
Characterizing the thermal environment of small mammals: what should we be measuring, and how?
}

This article was published in the following Dove Press journal:

Open Access Animal Physiology

9 September 2010

Number of times this article has been viewed

\section{Joy C Coleman \\ Colleen T Downs}

School of Biological and Conservation Sciences, Scottsville, Pietermaritzburg, South Africa
Correspondence: Colleen T Downs School of Biological and Conservation Sciences, P/Bag X0I, Scottsville, Pietermaritzburg, 3209, South Africa

Tel +2733260 5I 27

Fax +27332605105

Email downs@ukzn.ac.za
Abstract: Operative temperature and standard operative temperature have been proposed as providing an estimate of the thermal load experienced by endotherms and ectotherms. Common techniques of measuring operative temperature include black-bulb temperatures or simplified unheated metal models, typically made of copper. We quantified the thermal environment perceived by a small, arboreal rodent using a number of methods at three study sites in winter and summer. Our area of interest was how well these methods accurately portrayed the actual temperatures that small mammals are exposed to. We predicted that black-bulb and copper model temperatures would more accurately predict operative temperature during photophase when compared with other direct measurements/devices, and that black-bulb temperature would record the greatest variation in temperatures. Temperature differences between the methods were largest during the midday, when temperatures were highest. All methods recorded a greater range of temperatures during photophase than during scotophase. Black-bulb and model temperatures produced more accurate, rapid measurements when compared with measurements produced by direct temperature recording devices, particularly during photophase, when solar radiation is the major influence of heating. Other methods lagged behind black-bulb measurements. Although mean temperatures of some of the methods were significantly different, there was a high degree of correlation between all methods, even after randomization and generation of $25 \%$ and $10 \%$ subsamples. In studies requiring accurate time series measurements, it is suggested that black-bulb or copper models be employed rather than direct temperature recording devices. Simpler measurement devices would suffice for studies requiring an estimate of the temperature variation and trends in the microclimate of small mammals, particularly arboreal or cavity dwelling species.

Keywords: ambient temperature, operative temperature, black-bulb, model, small mammal, cavity dweller

\section{Introduction}

For an extended period, the importance of characterizing the thermal environment of ectotherms and endotherms has been documented, resulting in a range of physical model representations of study animals. However, few studies have discussed the applicability and/or relevance of these models to the particular research question. Moreover, recent advances in technology have resulted in a range of small temperature recording devices which might substitute for models depending on the type of data required. ${ }^{1}$ Such devices may lower both the cost and time consumed in producing operative temperature $\left(\mathrm{T}_{\mathrm{e}}\right)$ models, by providing accurate thermal indices at a scale relative to the study animal. 
Ambient temperature $\left(T_{a}\right)$ is not the actual thermal condition experienced by the animal in its natural environment. ${ }^{2-3}$ The factors of the environment which are primarily responsible for energy flow to an animal include radiation, air temperature, wind, and humidity. ${ }^{4}$ In order to estimate the energetic effects of the thermal regime an animal experiences in the field, it is convenient to integrate the effects of these parameters into an index value that can be directly compared with the animal's physiological performance. ${ }^{5}$ A useful index of the thermal potential driving heat flow between animals and their thermal environments is the $T_{e}{ }^{6}{ }^{6}$ This thermal index thus gives an indication of the thermal conditions experienced by an animal in its natural surroundings. ${ }^{2}$

Operative temperature is considered to be the temperature of an inanimate object of zero heat capacity that is of the same size, shape, and has the same radiative properties as the animal exposed to the same microclimate. ${ }^{7}$ Operative temperature would be the body temperature $\left(\mathrm{T}_{\mathrm{b}}\right)$ of an animal if it were in thermal equilibrium with the environment in the absence of metabolic heating or evaporative cooling. ${ }^{8}$ The difference between $T_{e}$ and $T_{b}$ equals the net thermal gradient acting on the animal, and the net effect of a homeotherm's heat production and evaporative water loss is to maintain $\mathrm{T}_{\mathrm{b}}$ different from $T_{e}{ }^{9}$ Once the $T_{e}$ has been determined for the particular natural microclimate in which one is interested, one may estimate the value of physiological and/or ecological variables of the animal which may have been expressed as a function of $\mathrm{T}_{\mathrm{e}}{ }^{10}$

Operative temperature can be distinguished from standard operative temperature $\left(T_{e s}\right)$, which by including $T_{b}$ in its definition, is a direct index of sensible heat flux. Unlike $\mathrm{T}_{\mathrm{e}}, \mathrm{T}_{\mathrm{es}}$ accommodates wind-induced changes in resistance to heat flow by normalization to standard (eg, metabolism chamber) convective conditions, ${ }^{11}$ thus avoiding the limitation of one convection condition. Standard operative temperature models have been used with less frequency than $T_{e}$ models ${ }^{8}$ as they are more difficult and time consuming to construct and their reliability has been called into question. ${ }^{12}$ In the present study, we used only $T_{e}$.

Operative temperatures ${ }^{7,13}$ have become a tool for studying the thermal effects of ectotherms and endotherms. ${ }^{3}$ Numerous physical model representations of animals have been used to measure $T_{e}$, and when used correctly, $T_{e}$ models have the potential to be an effective tool for examining the relationship between an animal's thermal environment and its physiology and ecology. ${ }^{8}$ The use of models is now expected in studies of field thermal physiology. ${ }^{14}$ Sphere thermometers may provide a reasonably accurate thermal index of an animal's environment, ${ }^{9}$ copper casts being the most accurate $\mathrm{T}_{\mathrm{e}}$ models available. ${ }^{8}$ Wall thickness and the size of both the model and the internal cavity of the model are important considerations for accuracy of readings. ${ }^{15}$ Rapid time response to varying thermal conditions can be obtained by using hollow copper objects, when the walls are of sufficient thickness (1-2 mm for animals up to $100 \mathrm{~g}$ ) to conduct heat and internal gradients are minor in small ( $<3 \mathrm{~cm}$ diameter) models. ${ }^{3}$ A comparative study ${ }^{9}$ indicated that painted metal spheres or cylinders are acceptable $T_{e}$ thermometers when multiple measurements over long time scales (several hours) are taken.

Thus, although a variety of physical model representations of animals have been used to measure $\mathrm{T}_{\mathrm{e}}$ (see Review), ${ }^{8}$ few studies have been designed to question whether the $T_{e}$ 's measured account for the range of temperatures to which the study animal is exposed in its multiple microhabitats. Many small mammals avoid daytime hours when solar radiation is at its greatest by sheltering in burrows or by adopting nocturnal activity patterns. ${ }^{16}$ In such cases, it would be less appropriate to use metal models or black-bulbs placed in the sun and more relevant to use multiple temperature recording devices which would provide accurate thermal indices of the microclimate of the study animal. In addition, few studies have compared measurements obtained using different temperature measuring devices, now available in the market, in the field. In an attempt to determine the utility of electronic devices versus models in field studies, ${ }^{1}$ it was found that electronic devices produced sets of $T_{e}$ 's almost identical to lizard models, suggesting that the devices can be substituted for models in certain applications.

The objective of this study was to quantify the degree to which temperature data derived using 1) copper models, 2) black-bulb, and 3) direct measurement devices accurately represent the temperatures perceived by small mammals using the nocturnal black-tailed tree rat, Thallomys nigricauda, as a representative species. This species was chosen since it inhabits a wide range of habitats from mesic to xeric localities, this distribution resulting in a wide range of temperatures to which it is exposed. In addition, being arboreal, T. nigricauda is exposed to greater temperature fluctuations than burrowing small mammals in southern Africa. ${ }^{17-20} \mathrm{We}$ predicted that black-bulb and copper model temperatures would more accurately and precisely predict $T_{e}$ during the day when compared with other direct measurement devices and that black-bulb would record the greatest variation in temperatures. We compared the methods for measuring $\mathrm{T}_{\mathrm{e}}$ across seasons as many ecophysiological studies are interested in 
seasonal effects. Furthermore, we were interested if for one species that has a broad range whether the different methods would show similar responses.

\section{Materials and methods Study sites}

The study was conducted at three study sites in southern Africa during winter (June-July) 2006 and 2007 and summer (January-February) 2007. These were, Weenen Game Reserve in the KwaZulu-Natal Province, South Africa (28 50'43'S; 2959'12'E), Molopo Nature Reserve in the North-West Province, South Africa (2550'52's; 22 55'37’E), and Haina Game Farm in Botswana (2056’56”'S; 2340’40”E). Altitude and degree location were plotted using a Magellan GPS 4000 XL. These study sites were chosen as part of a broader study on aspects of physiology and behavior of T. nigricauda along an aridity gradient. Data were recorded at each site for an average of three days in winter and five days in summer with no data collected on days if it was overcast or rainy. More days were collected for as there was more variation between minimum and maximum temperatures each day. All climatic instruments and models were placed at a single location at each study site known to be occupied by study animals, and the same instruments and models were used in the three respective study sites.

\section{Ambient temperatures}

Ambient temperature was measured at each site in three ways. Firstly using a calibrated Thermocron iButton ${ }^{\circledR}$ (model DS1922L-F5 Thermochron resolution $0.5^{\circ} \mathrm{C}$ from $-10^{\circ} \mathrm{C}$ to $+65^{\circ} \mathrm{C}$; Dallas SemiConductor; Maxim, Sunnyvale, CA) placed in a Stevenson's screen (radiation shield). iButtons ${ }^{\circledR}$ were calibrated with mercury thermometers $\left(0.05^{\circ} \mathrm{C}\right)$ in a water bath at temperatures from 5 to $45^{\circ} \mathrm{C}$. The shields were placed at a height of 1.25-2 m, recording shade temperature. (In all figures, this measurement is referred to as 'shade'). Secondly, a single, exposed iButton ${ }^{\circledR}$ was also placed on the top of a tree branch at a height of $1.5 \mathrm{~m}$. The iButtons ${ }^{\circledR}$ were programed to record temperatures every $15 \mathrm{~min}$. (In all figures, this measurement is referred to as 'iButton'). It must be noted that as each iButton ${ }^{\circledR}$ is stainless steel it has its own thermal properties and so the position of these would affect their measurements. Thirdly, $\mathrm{T}_{\mathrm{a}}$ was measured using a pre-calibrated Kestrel 4000 Pocket Weather Tracker (Nielsen Kellerman, Boothwyn, PA). This instrument was secured on to a tree at a height of $1.5 \mathrm{~m}$ and programed to record temperatures at four intervals each hour. (In all figures, this measurement is referred to as 'Kestrel').

\section{Operative environmental temperature measurements}

We measured black-bulb solar radiation temperatures (abbreviated as 'Bbulb' in all figures) using an iButton ${ }^{\circledR}$ placed in a black copper ball ( $1 \mathrm{~mm}$ thickness, $10 \mathrm{~cm}$ diameter) that was exposed to direct sunlight throughout the day at a height of $1 \mathrm{~m}$.

Heated mounts (required for $\mathrm{T}_{\mathrm{es}}$ ) cannot be used when the operative temperature of the environment exceeds body temperature. ${ }^{21}$ Physical models of T. nigricauda were constructed from hollow, copper pipes (cylinders). The proportions of the model approximated those of an average T. nigricauda adult (length: $13 \mathrm{~cm}$, diameter: $3.2 \mathrm{~cm}$ ). A guide ${ }^{15}$ is provided for the minimum wall thickness to reduce thermal heterogeneity of model temperatures. Models had a wall thickness of $2 \mathrm{~mm}$ and were painted black as virtually all animals and flat paints are effectively black. ${ }^{13}$ Internal temperatures of the copper models were measured using calibrated DS1921 Thermocron iButtons ${ }^{\circledR}$ suspended in the centre of each model using cotton to determine $\mathrm{T}_{\mathrm{e}}$. Temperature resolution of iButtons ${ }^{\circledR}$ was $0.5^{\circ} \mathrm{C}$. iButtons ${ }^{\circledR}$ were programed to record temperature every $15 \mathrm{~min}$. Before moving the models to their sites, they were lined up on the ground and allowed to equilibrate 15-20 min (equilibration under full solar exposure takes $\pm 10 \mathrm{~min}$ ) and since all models were in place at the sites for the entire course of the study they had invariably equilibrated well over the required 10 min before every temperature measurement. ${ }^{22}$

Two copper models were placed in permanent positions at each study site. One was placed in a tree at a height of $1.5 \mathrm{~m}$ (referred to as 'model (elevated)' in all figures). The second was placed at the base of the tree and referred to as 'model (base)' in all figures. Copper models in trees were attached in two places, to the top of a branch using copper wire.

\section{Data analyses}

Kestrel data were downloaded using the Kestrel Interface Communication Software Version 1.12. iButton ${ }^{\circledR}$ data were downloaded using the DS1921 Thermochron iButton ${ }^{\circledR}$ Software Download Programme (Dallas SemiConductor; Maxim). Statistical analyses including descriptive statistics, regressions, and randomization were performed using the Statistica 7 package (Statsoft Inc, Tulsa, OK). As the data represented a time series of values, adjacent values were possibly autocorrelated. To reduce the effect of the lack of independence, samples were randomized. We then performed 1000 replicates on $25 \%$ and $10 \%$ sub-samples from the randomized dataset for statistical analysis. 


\section{Results}

Temperatures measured using all methods revealed five important patterns. Firstly, temperature differences between the methods were largest during the midday, when temperatures were high, resulting in significant differences between most methods during photophase but lack of significant differences between most methods during scotophase (Table 1, Figures 1 and 2). Secondly, all methods recorded a greater range of temperatures during photophase than during scotophase (Figures 1 and 2). Thirdly, most methods had slower heating and cooling rates (indicated by the slope of increase in temperature per unit time) when compared with the black-bulb (Figures 1 and 2). The fourth pattern apparent was that although the mean temperatures of some of the methods were significantly different, there was a high degree of correlation between all methods (Table 2, Figures 3 and 4). In general, measures of the various temperatures using the respective methods showed similar accuracy. However, black-bulb and models showed greater precision and accuracy than direct measurement devices at short time-scales during photophase.

Mean winter temperatures for all climatic variables at the three study sites showed that there were no significant

Table I Mean, range, minimum and maximum temperatures $\left({ }^{\circ} \mathrm{C}\right)$ measured using different methods during winter and summer at the three study sites (see text for abbreviations and explanations)

\begin{tabular}{|c|c|c|c|c|c|c|}
\hline$\overline{\text { Site }}$ & Variable & $\mathbf{N}$ & Mean & Minimum & Maximum & Range \\
\hline \multicolumn{7}{|l|}{ Winter } \\
\hline \multirow[t]{6}{*}{ Molopo } & Black bulb & 283 & $11.70 \pm 0.66$ & -5.39 & 33.68 & 39.07 \\
\hline & model (base) & 283 & $10.98 \pm 0.46$ & -0.92 & 25.65 & 26.57 \\
\hline & model (elevated) & 283 & $10.38 \pm 0.44$ & -3.40 & 25.20 & 28.60 \\
\hline & shade & 283 & $10.09 \pm 0.47$ & -4.47 & 25.17 & 29.64 \\
\hline & iButton & 283 & $10.18 \pm 0.38$ & -1.93 & 22.62 & 24.55 \\
\hline & Kestrel & 283 & $9.80 \pm 0.4 \mathrm{I}$ & -3.90 & 22.70 & 26.60 \\
\hline \multirow[t]{5}{*}{ Haina } & Black bulb & 376 & $17.76 \pm 0.66$ & 2.06 & 42.08 & 40.02 \\
\hline & shade & 376 & $15.55 \pm 0.43$ & 3.13 & 30.68 & 27.55 \\
\hline & iButton & 376 & $16.94 \pm 0.33$ & 6.00 & 31.00 & 25.00 \\
\hline & model (base) & 376 & $19.55 \pm 0.55$ & 7.10 & 42.60 & 35.50 \\
\hline & Kestrel & 376 & $15.56 \pm 0.40$ & 3.60 & 33.60 & 30.00 \\
\hline \multirow[t]{6}{*}{ Weenen } & Black bulb & 440 & $|6.5| \pm 0.42$ & 5.10 & 39.14 & 34.04 \\
\hline & shade & 440 & $14.10 \pm 0.26$ & 4.60 & 27.66 & 23.06 \\
\hline & model (base) & 269 & $15.29 \pm 0.24$ & 8.61 & 25.16 & 16.55 \\
\hline & model (elevated) & 270 & $14.69 \pm 0.22$ & 8.18 & 23.73 & 15.55 \\
\hline & iButton & 199 & $14.24 \pm 0.28$ & 8.12 & 24.14 & 16.02 \\
\hline & Kestrel & 440 & $13.97 \pm 0.25$ & 5.20 & 29.80 & 24.60 \\
\hline \multicolumn{7}{|l|}{ Summer } \\
\hline \multirow[t]{6}{*}{ Molopo } & Black bulb & 498 & $29.26 \pm 0.33$ & 19.16 & 49.10 & 29.94 \\
\hline & Shade & 498 & $27.96 \pm 0.24$ & 19.68 & 38.67 & 18.99 \\
\hline & model (elevated) & 498 & $28.59 \pm 0.28$ & 19.21 & 43.17 & 23.96 \\
\hline & model (base) & 498 & $27.94 \pm 0.23$ & 20.65 & 45.60 & 24.95 \\
\hline & iButton & 498 & $29.37 \pm 0.32$ & 19.35 & 52.33 & 32.98 \\
\hline & Kestrel & 498 & $27.72 \pm 0.24$ & 19.10 & 40.50 & 21.40 \\
\hline \multirow[t]{9}{*}{ Haina } & Black bulb & 440 & $26.35 \pm 0.30$ & 16.61 & 42.58 & 25.97 \\
\hline & shade & 440 & $25.48 \pm 0.22$ & 16.67 & 34.67 & 18.00 \\
\hline & iButton & 440 & $26.03 \pm 0.19$ & 19.12 & 34.11 & 14.99 \\
\hline & model (base) & 440 & $26.60 \pm 0.17$ & 20.66 & 36.65 & 15.99 \\
\hline & model (elevated) & 440 & $26.35 \pm 0.29$ & 17.05 & 45.05 & 28.00 \\
\hline & Kestrel & 440 & $25.09 \pm 0.22$ & 16.80 & 34.50 & 17.70 \\
\hline & Black bulb & 488 & $23.13 \pm 0.30$ & 11.63 & 41.13 & 29.50 \\
\hline & shade & 488 & $22.03 \pm 0.29$ & 11.13 & 36.65 & 25.52 \\
\hline & model (base) & 488 & $23.04 \pm 0.24$ & 14.14 & 35.65 & 21.51 \\
\hline \multirow{3}{*}{ Weenen } & model (elevated) & 488 & $22.40 \pm 0.29$ & 11.19 & 38.21 & 27.02 \\
\hline & iButton & 488 & $22.65 \pm 0.23$ & 13.13 & 34.14 & 21.01 \\
\hline & Kestrel & 488 & $21.75 \pm 0.28$ & 11.10 & 36.50 & 25.40 \\
\hline
\end{tabular}


A

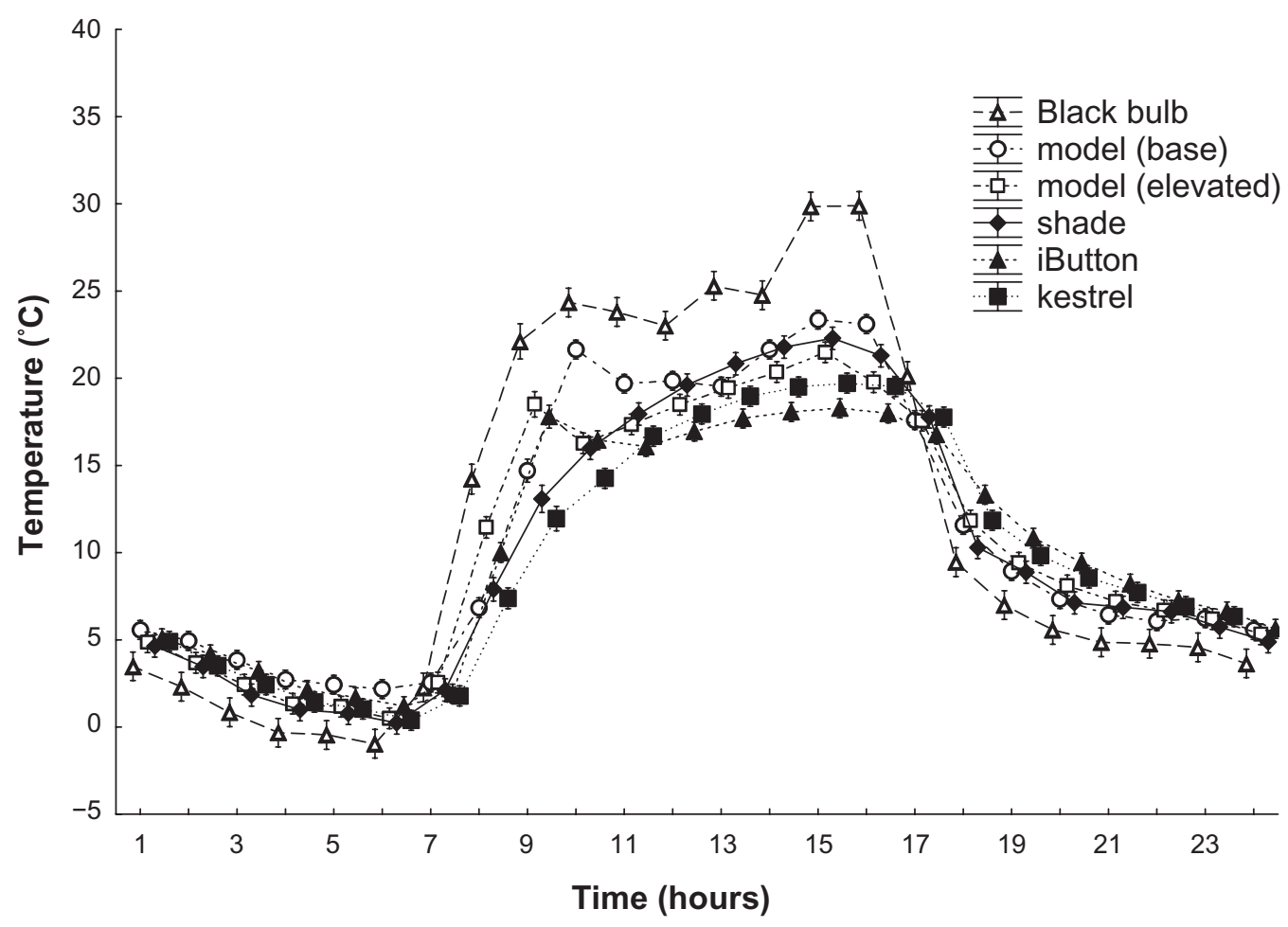

B

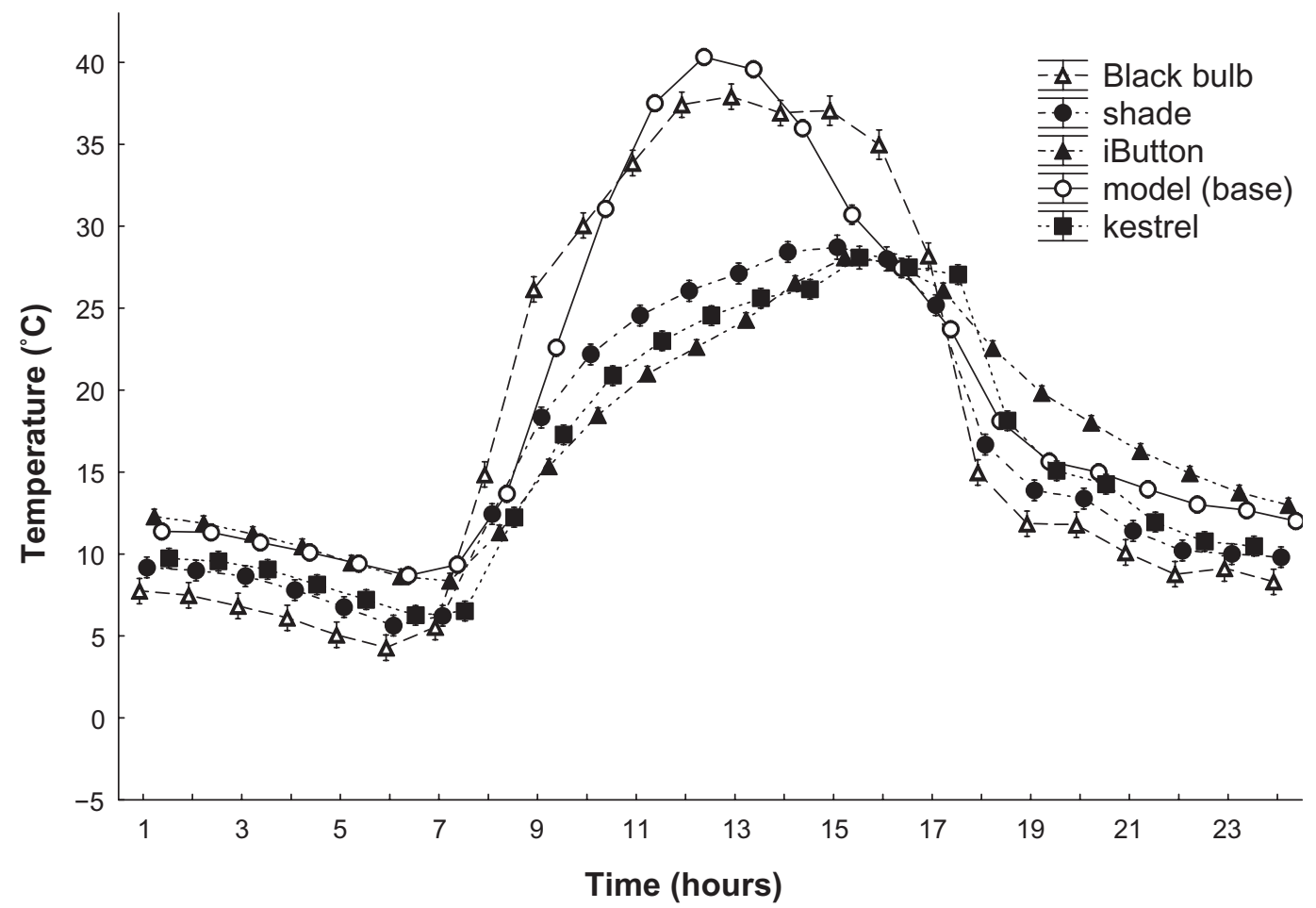

Figure I (Continued) 
C

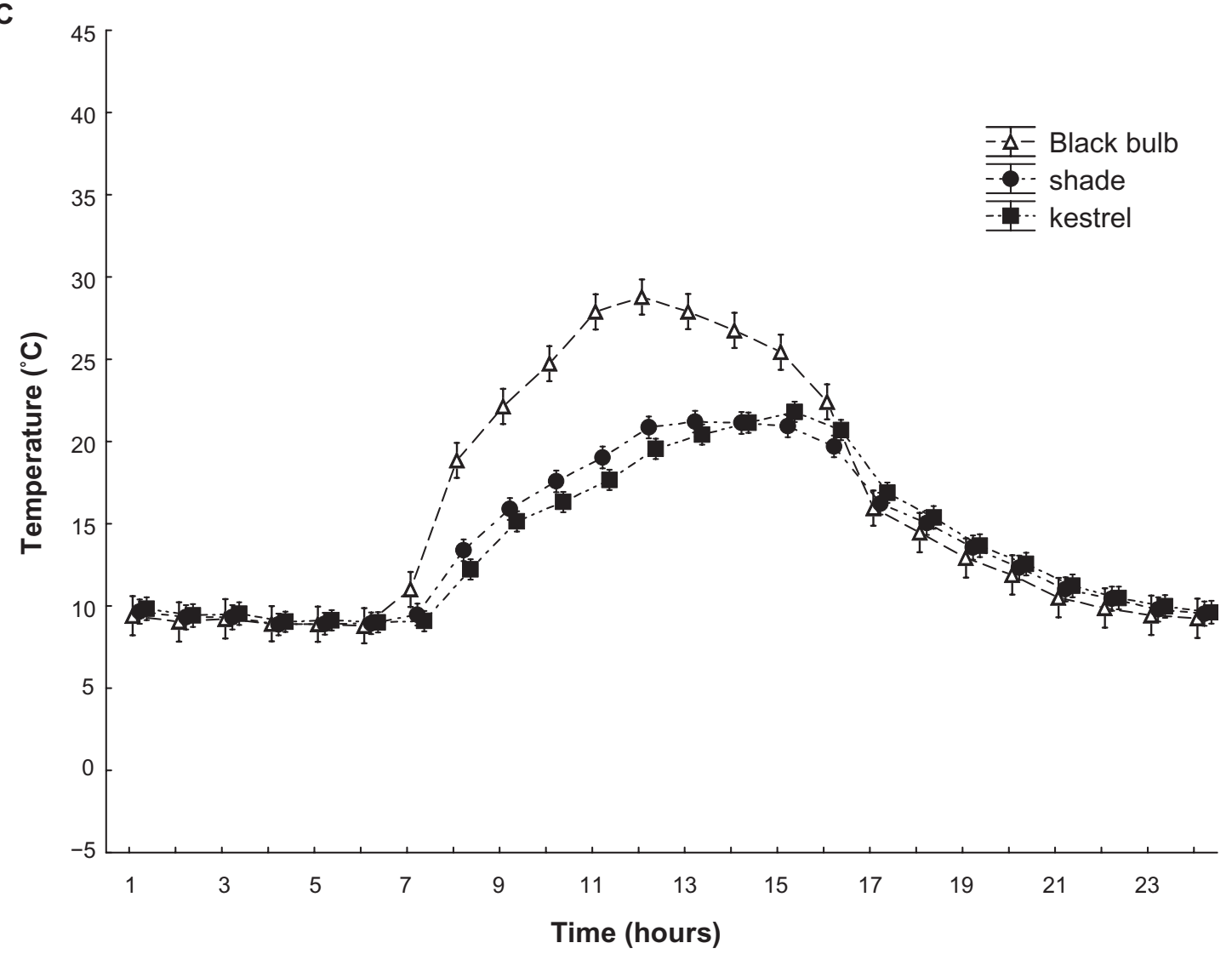

Figure I Mean winter temperatures $( \pm \mathrm{SE})$ in Molopo (A), Haina (B), and Weenen (C). No data were recorded for model (elevated) in Haina. Weenen model (elevated), model (base), and iButton ${ }^{\oplus}$ data were excluded due to incomplete datasets (see text for abbreviations and explanations).

A

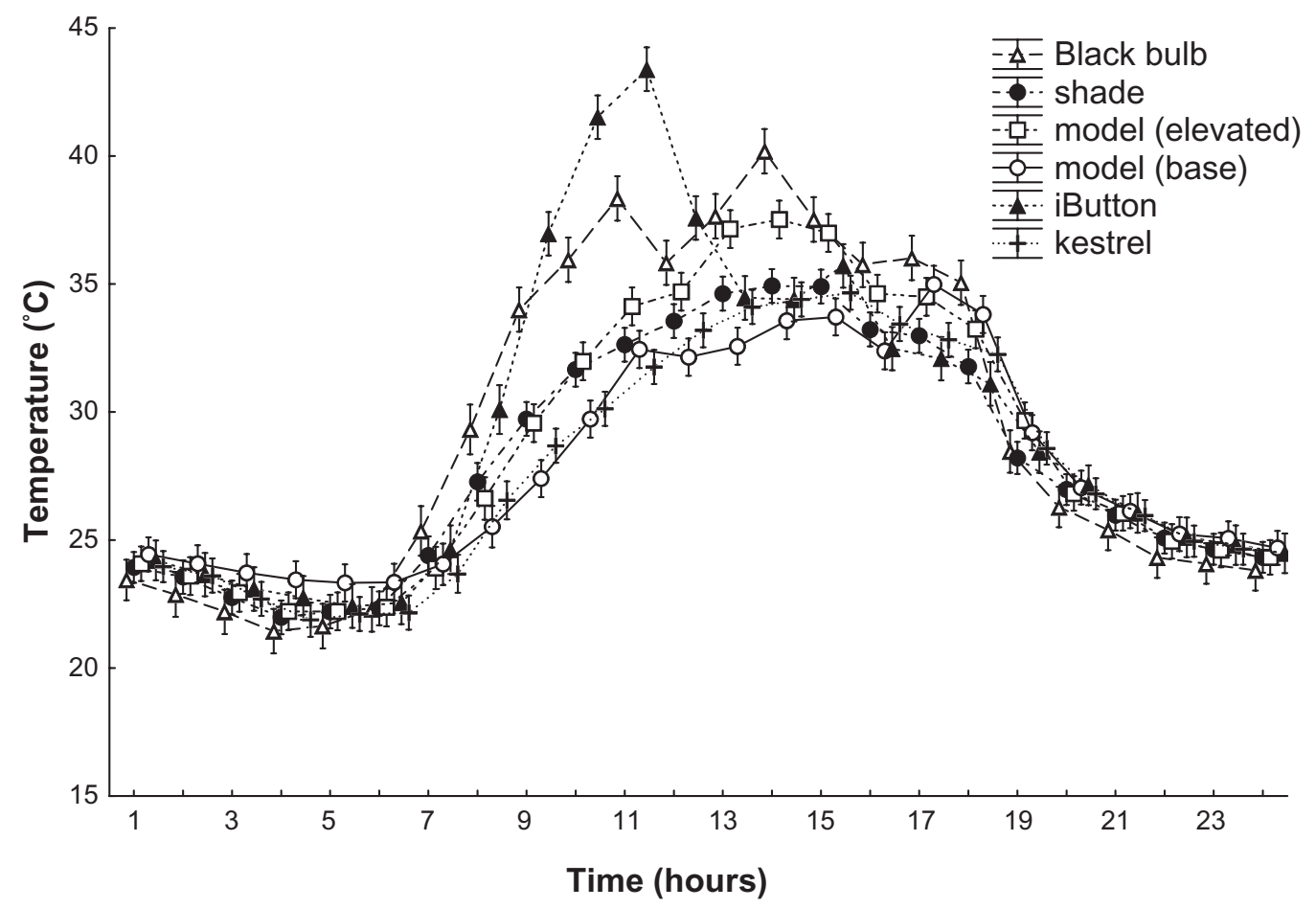

Figure 2 (Continued) 

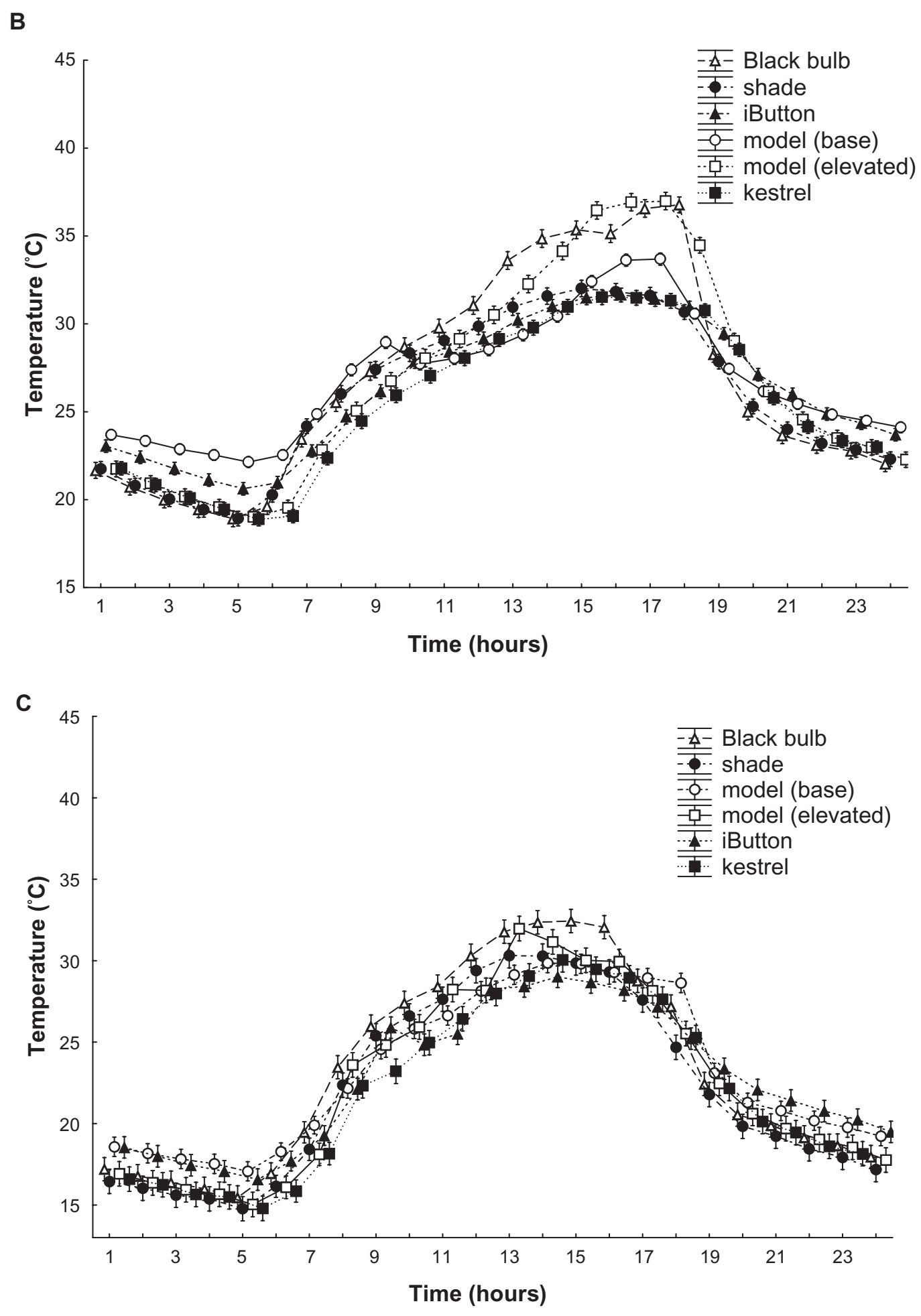

Figure 2 Mean summer temperatures $( \pm \mathrm{SE})$ in Molopo (A), Haina (B), and Weenen (C).

differences between most methods during the night, while differences were significant for most methods during the day (Figure 1). Black-bulb accounted for the highest mean, highest maximum, lowest minimum, and greatest range, with the exception of Weenen, where shade temperature recorded the lowest minimum temperature (Table 1). Temperature ranges of all variables were greater during photophase than scotophase at all sites, although this difference was less apparent at Weenen (Figure 1). In winter black-bulb had a greater temperature range at all sites when compared with models (Table 1). 
Table 2 Relationship between temperatures produced by different methods at all sites during winter and summer (see text). Values are $R^{2}$ values for $25 \%$ sub-sample of the dataset. $R^{2}$ values for $10 \%$ sub-sample of the dataset are shown in parenthesis when they differ from the $25 \%$ sub-sample. Blanks indicate missing model (elevated) dataset for Haina in winter. The Weenen dataset for winter was excluded due to an incomplete dataset

\begin{tabular}{|c|c|c|c|c|c|}
\hline \multirow[t]{2}{*}{ Comparison } & \multicolumn{2}{|l|}{ Winter } & \multicolumn{3}{|l|}{ Summer } \\
\hline & Molopo & Haina & Molopo & Haina & Weenen \\
\hline Bbulb v Kestrel & 0.89 & 0.90 & 0.87 & 0.94 & 0.97 \\
\hline Bbulb v model (base) & 0.94 & 0.93 & $0.8 \mathrm{I}(0.82)$ & 0.89 & 0.96 \\
\hline Bbulb v model (elevated) & 0.95 & & 0.91 & 0.96 & 0.96 \\
\hline Bbulb v iButton & 0.89 & 0.72 & $0.79(0.80)$ & 0.89 & 0.94 \\
\hline Bbulb v shade & 0.94 & 0.95 & $0.91(0.92)$ & 0.94 & 0.98 \\
\hline Model (base) v Kestrel & 0.93 & 0.80 & 0.89 & $0.87(0.88)$ & 0.94 \\
\hline Model (base) v iButton & 0.90 & $0.64(0.65)$ & $0.62(0.63)$ & 0.84 & 0.91 \\
\hline Model (elevated) $\vee$ Kestrel & 0.96 & & 0.96 & 0.95 & 0.97 \\
\hline Model (elevated) v model (base) & 0.92 & & $0.90(0.91)$ & 0.92 & 0.92 \\
\hline Model (elevated) v iButton & 0.97 & & $0.7 \mid(0.72)$ & 0.92 & 0.95 \\
\hline iButton v Kestrel & 0.94 & 0.90 & $0.69(0.70)$ & 0.97 & 0.96 \\
\hline Shade v Kestrel & $0.92(0.98)$ & $0.86(0.98)$ & $0.77(0.97)$ & $0.92(0.96)$ & $0.96(0.98)$ \\
\hline Shade v model (base) & $0.95(0.96)$ & 0.86 & $0.88(0.89)$ & 0.89 & 0.93 \\
\hline Shade $v$ model (elevated) & 0.96 & & 0.96 & 0.93 & 0.97 \\
\hline Shade v iButton & $0.95(0.92)$ & 0.86 & $0.88(0.78)$ & $0.89(0.92)$ & $0.93(0.96)$ \\
\hline
\end{tabular}

Similar to winter, mean summer temperatures for all climatic variables at the three study sites showed lack of significant differences between most methods during the night, while differences were significant for most methods during photophase (Figure 2). Highest mean, highest maximum temperatures, and the greatest temperature range were recorded by iButton ${ }^{\circledR}$ in Molopo. Lowest minimum temperatures were recorded by Kestrel at both Molopo and Weenen, while black-bulb recorded the lowest minimum temperature at Haina (Table 1). Similarly to winter, temperature ranges of all variables were greater during photophase than scotophase at all sites (Figure 2). In summer, black-bulb had a greater

A

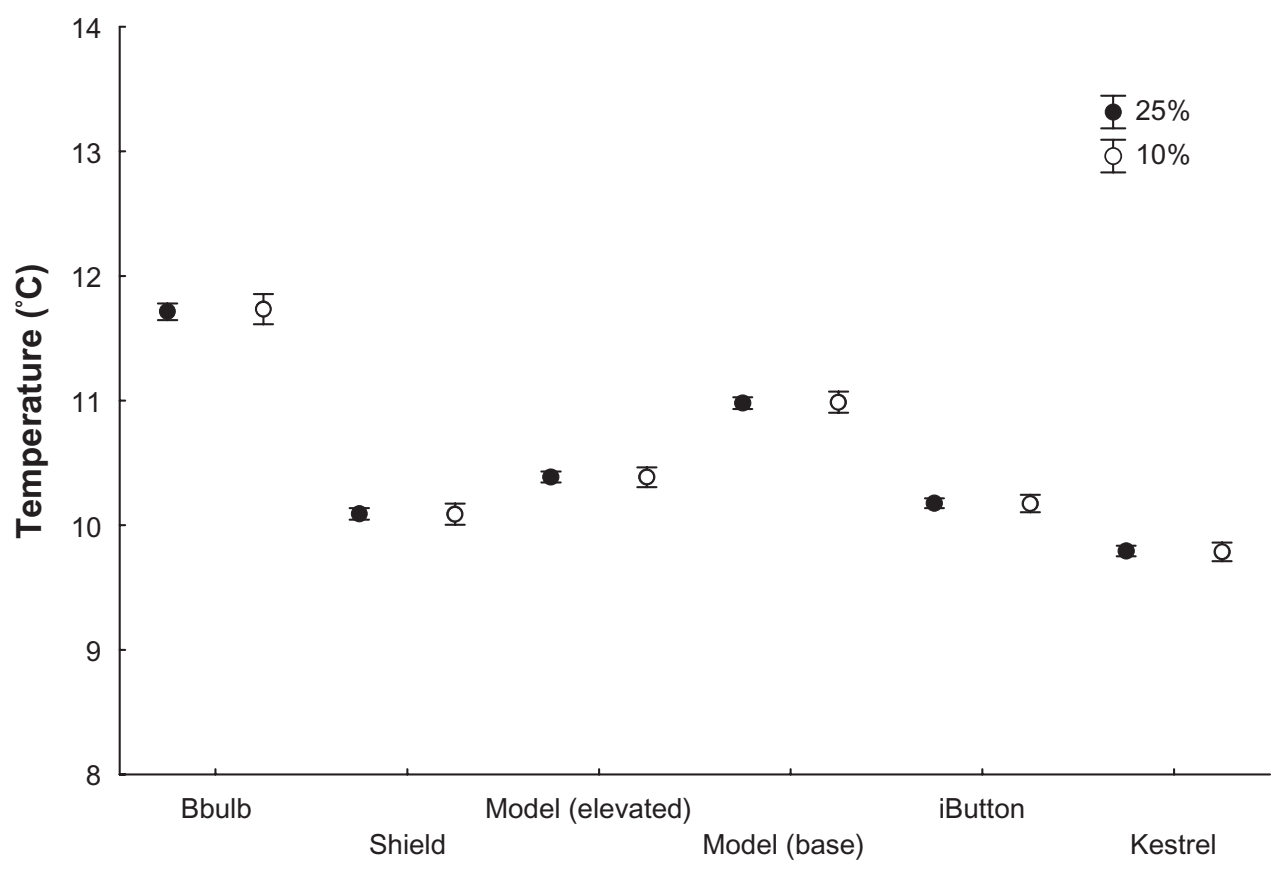

Method

Figure 3 (Continued) 
B

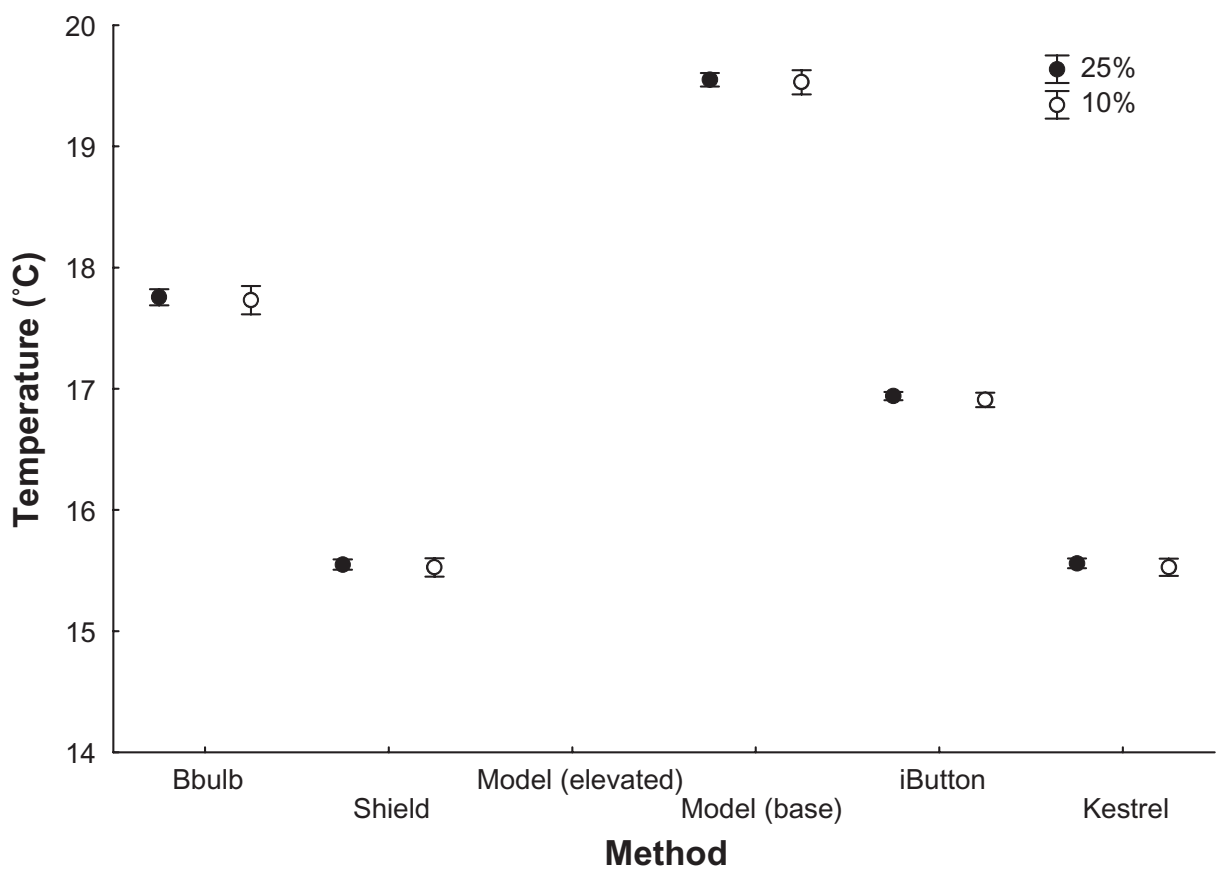

C

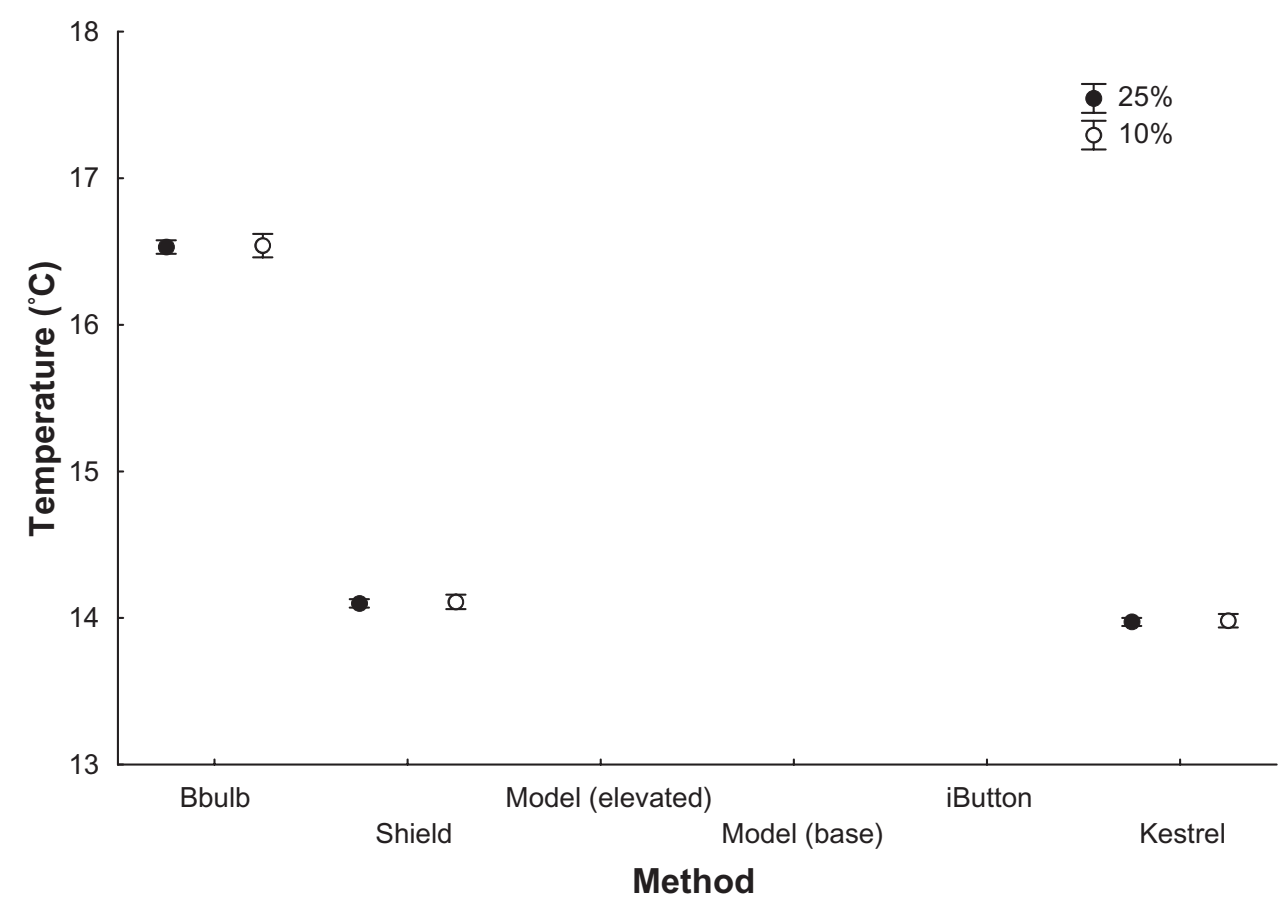

Figure 3 Mean winter temperatures $( \pm 95 \% \mathrm{Cl})$ in Molopo $(\mathbf{A})$, Haina (B), and Weenen $(\mathbf{C})$ after randomization. No data were recorded for model (elevated) in Haina. Weenen model (elevated), model (base), and iButton ${ }^{\circledR}$ data were excluded due to incomplete datasets. Note small confidence intervals.

temperature range at all sites when compared with models, with the exception of Haina, where model (elevated) recorded a greater temperature range than black-bulb (Table 1).

Mean temperatures for randomized data for $25 \%$ and $10 \%$ sub-samples of all methods for winter (Figure 3 ) and summer (Figure 4) showed that there was little difference between the means of the $25 \%$ and $10 \%$ sub-samples for each method, as shown by the overlap of the $95 \%$ confidence intervals in the respective figures. Moreover, there was little difference between the means of the sub-samples and the 
means calculated from the full dataset (Table 1, Figures 3

and 4). Although there were significant differences between the temperature means of different methods (Figures 3 and 4), there were no noticeable trends.
Even after randomization and generation of $25 \%$ and $10 \%$ sub-samples, all methods showed a high correlation (Table 2). In addition, there was little difference between the $25 \%$ and $10 \%$ sub-samples of correlations between methods (Table 2),

A

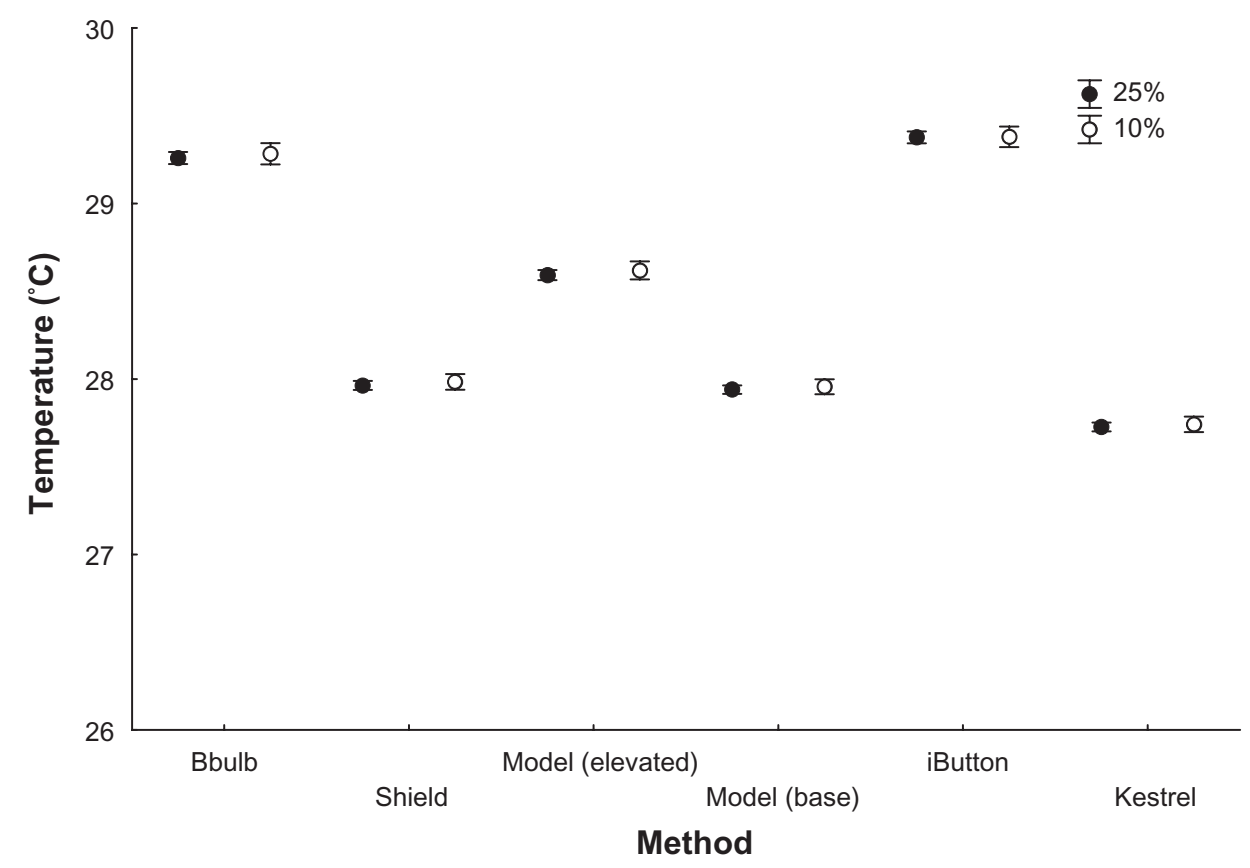

B

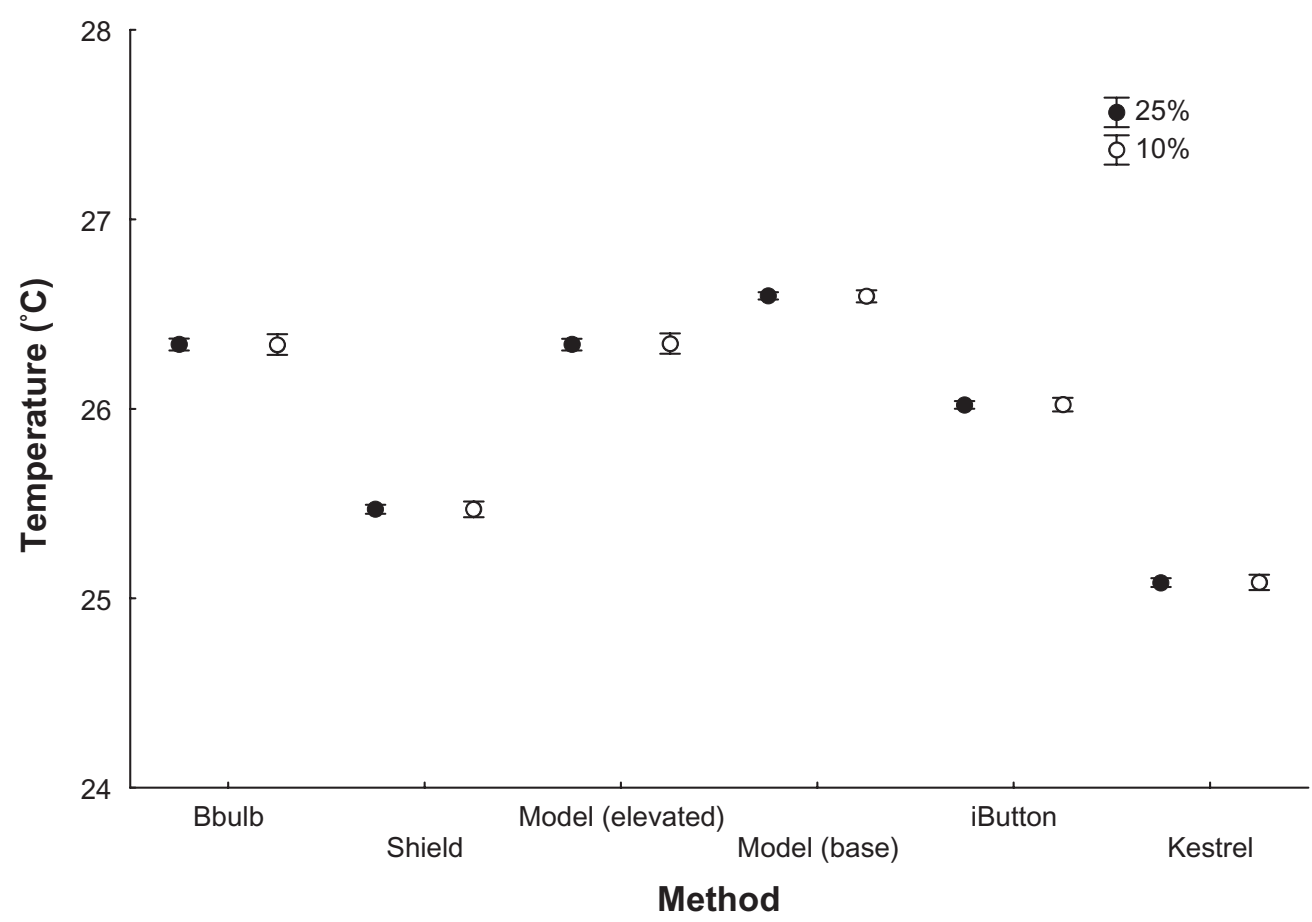

Figure 4 (Continued) 


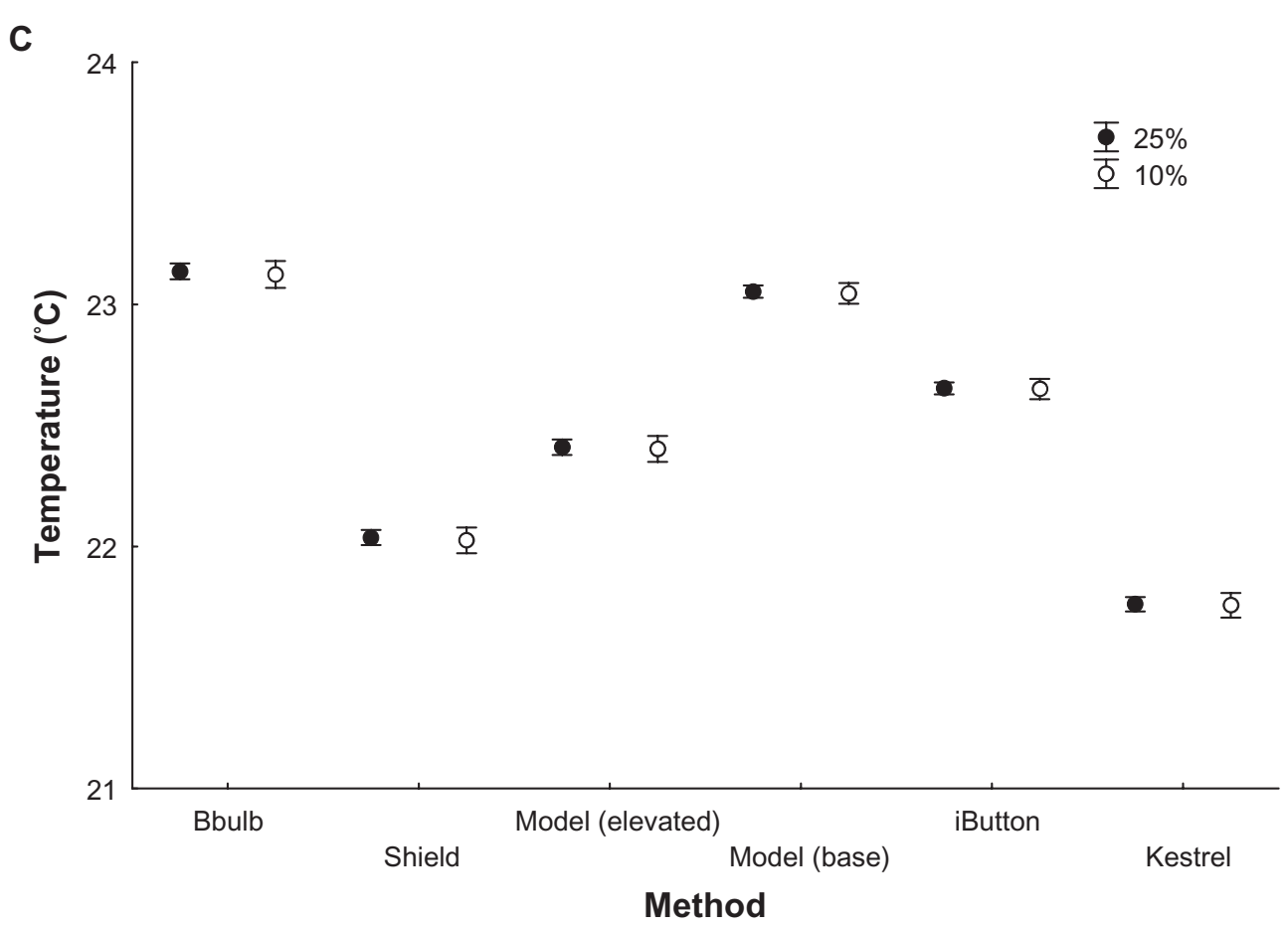

Figure 4 Mean summer temperatures $( \pm 95 \% \mathrm{Cl})$ in Molopo $(\mathbf{A})$, Haina $(\mathbf{B})$, and Weenen $(\mathbf{C})$ after randomization. Note small confidence intervals.

which indicated that there was similarity in response of direct measurement devices and models to changing temperature.

\section{Discussion}

Significant differences during photophase and the lack of significant differences during the scotophase can be attributed to the influence of solar radiation on methods used. Changes in black-bulb and models had a high dependence on solar radiation and thus these heated up to higher temperatures during the photophase when compared with other direct devices. During scotophase, these methods measure similar temperatures to direct temperature recording devices, due to the lack of solar radiation. This accounted for the greater range of temperatures measured during photophase compared with scotophase. However, the position of models has an influence on temperatures measured. The influence of solar radiation can induce variation of $5^{\circ} \mathrm{C}$ or more in temperatures measured in thin-walled $\mathrm{T}_{\mathrm{e}}$ models depending on how the sun strikes the model ${ }^{15}$ Models placed below or in a tree received shade at least for part of the day and thus did not reach the maximum temperatures reached by the black-bulb. For small mammals, like T. nigricauda, which avoid the hours of the day when solar radiation is at its greatest by sheltering in burrows/ cavities or by adopting nocturnal activity patterns, it would be less appropriate to use metal models or black-bulbs placed in the sun and more relevant to use multiple temperature recording devices which would provide accurate thermal indices of the microclimate of study animals. Similarly, other studies have shown that habitat-level measurements do not always correspond to niche-level measurements. ${ }^{23-24}$

The slower rates of heating and cooling in all methods when compared with black-bulb temperature changes were likely due to the position of the measuring devices and/or as they are less affected by solar radiation. The direct devices in this study did produce temperature profiles similar to those of the black-bulb and models. However, direct measurements appeared to change temperature more slowly than the black-bulb and models and reached different equilibrium temperatures. Although this violates one of the classical requirements for physical $\mathrm{T}_{\mathrm{e}}$ models $^{3,7}$ and would clearly be a problem when one's research question demands accurate time series measurements, animal $\mathrm{T}_{\mathrm{b}}$ would always lag behind model $\mathrm{T}_{\mathrm{e}}$ in the field. ${ }^{8}$ This is thus a consideration for studies using $\mathrm{T}_{\mathrm{e}}$ against which to compare animal $\mathrm{T}_{\mathrm{b}}$.

All methods show similarity in response to temperature, as indicated by the high correlations, but differ in the maximum and minimum temperatures attained as well as in the heating and cooling rates, as indicated by the means of the full dataset as well as the randomized dataset. We expected mean temperatures between methods to differ since each method differs with respect to the dependence on solar radiation, as well as the positioning in the field. 
As predicted, black-bulb and copper model temperatures did provide the most accurate and precise measure of $\mathrm{T}_{\mathrm{e}}$ during photophase when compared with other direct measurement devices, and black-bulb recorded the greatest variation in temperatures. However, all methods were accurate for general trends in terms of the thermal microenvironment. Black-bulb and copper models should be the favored devices for studies requiring accurate time series measurements, due to their rapid response to thermal change. In accordance with Vitt and Sartorius, ${ }^{1}$ we suggest that direct methods should be avoided in studies requiring accurate time series measurements. However, the utility of black-bulb and copper models is limited to studies on diurnal mammals or birds where the researcher is interested in the maximum temperatures reached during photophase and the effect of these temperatures on behavioral thermoregulation, for example. For studies on nocturnal and/or diurnal mammals that avoid the maximum daytime temperatures in refugia, simple direct measurement devices, such as iButtons ${ }^{\circledR}$ would produce accurate thermal profiles of temperatures to which the animal is exposed. Although temperatures of such devices may not provide an estimate of 'instantaneous' operative temperatures, they still show the variation in temperature available to the animal in the same microhabitat, since they respond faster than animal temperatures. ${ }^{15}$ If devices are placed in all the microhabitats used by the study animal, they may provide a reference thermal map of the areas that may explain the behavior of the study species. In particular, this may elucidate heterogeneity in $\mathrm{T}_{\mathrm{e}}$, which might be useful to understanding the biology, particularly ecophysiology and behavior of the study animal.

In conclusion, the decision as to whether $\mathrm{T}_{\mathrm{e}}$ should be measured as opposed to a direct measurement of the microclimate of the study animal depends on the research question. For studies necessitating instantaneous measurements of the diurnal thermal environment, it is suggested that $\mathrm{T}_{\mathrm{e}}$ is measured using a black-bulb or suitable models. However, simpler direct temperature measurement devices would suffice for studies requiring an estimate of the temperature trends of the microclimate of the study animal.

As mentioned there are currently a great variety of $T_{e}$ measurement methods, and very few research efforts are being made to independently compare and analyze these methods. We have attempted to address this here. Knowledge of these then allows interpretation of changes in $T_{e}$ and relates that to the biological significance or effect on the study animal.

\section{Acknowledgments}

We wish to thank our field assistants for their help in the field, and the management and staff of Weenen Game Reserve,
Molopo Nature Reserve, and Haina Game Farm for the use of their properties. We are grateful to the National Research Foundation for funding (Grant 65723) and to Mazda Wildlife for vehicle support.

\section{Disclosure}

No conflicts of interest were declared in relation to this paper.

\section{References}

1. Vitt LJ, Sartorius SS. HOBOs, tidbits and lizard models: the utility of electronic devices in field studies of ectotherm thermoregulation. Funct Ecol. 1999;13:670-674.

2. Chappell MA, Bartholomew GA. Standard operative temperature and thermal energetics of the Antelope ground squirrel Ammospermophilus leucurus Physiol Zool. 1981;54:81-93.

3. Bakken GS. Measurement and application of operative and standard operative temperatures in ecology. Am Zool. 1992;32:194-216.

4. Porter WP, Gates DM. Thermodynamic equilibria of animals with environment. Ecol Monogr. 1969;39:227-244.

5. Chappell MA. Standard operative temperatures and cost of thermoregulation in the Arctic ground squirrel. Spermophilus undulatus Oecologia. 1981;49:397-403

6. Byman D. Thermoregulatory behaviour of a diurnal small mammal, the Wyoming ground squirrel (Spermophilus elegans). Physiol Zool. 1985;58:705-718.

7. Bakken GS, Gates DM. Heat Transfer Analysis of Animals: Some implications for field ecology, physiology, and evolution. New York, NY: Springer-Verlag: 1975.

8. Dzialowski EM. Use of operative temperature and standard operative temperature models in thermal biology. $J$ Thermal Biol. 2005;30:317-334

9. Walsberg GE, Weathers WW. A simple technique for estimating operative environmental temperature. J Thermal Biol. 1986;11:67-72.

10. Morhardt S, Gates D. Energy-exchange analysis of the Belding ground squirrel and its habitat. Ecol Monogr. 1974;44:17-44.

11. Bakken GS. The use of standard operative temperature in the study of the thermal energetics of birds. Physiol Zool. 1980;53:108-119.

12. Walsberg G, Wolf B. An appraisal of operative temperature mounts as tools for studies of ecological energetics. Physiol Zool. 1996;69:658-681.

13. Bakken GS. A heat transfer analysis of animals: unifying concepts and the application of metabolism chamber data to field ecology. JThermal Biol. 1976;60:337-384.

14. Goldstein DL, Pinshow B. Taking physiology to the field: Using physiological approaches to answer questions about animals in their environment. Physiol Biochem Zool. 2006;79:237-241.

15. O’Connor M, Zimmerman L, Dzialowski E, Spotila J. Thick-walled physical models improve estimates of operative temperatures for moderate to large-sized reptiles. J Thermal Biol. 2000;25:293-304.

16. Nowak RM. Walker's Mammals of the World (6th ed). Baltimore, MD: The John Hopkins University Press: 1999.

17. de Graaf G. The Rodents of Southern Africa. Pretoria, South Africa: Butterworths: 1981.

18. Lovegrove BG, Knight-Eloff A. Soil and burrow temperatures, and the resource characteristics of the social mole-rat Cryptomys damarensis (Bathyergidae) in the Kalahari Desert. J Zool, Lond. 1988;216:403-416.

19. Downs CT, Perrin MR. An investigation of the macro- and microenvironments of four Gerbillurus species. Cimbebasia. 1989;11: 41-54.

20. Skinner JD, Chimimba CT. The Mammals of the Southern African Subregion (3rd edn). Cambridge, MA: Cambridge University Press: 2005. 
21. Bakken GS, Erskine DJ, Santee WR. Construction and operation of heated taxidermic mounts used to measure standard operative temperature. Ecology. 1983;64:1658-1662.

22. Salzman AG. The selective importance of heat stress in gull nest location. Ecology. 1982;63:742-751.
23. Helmuth BST. Intertidal mussel microclimates: Predicting the body temperature of a sessile invertebrate. Ecol Monogr. 1998;68:51-74.

24. Gilman SE, Wethey DS, Helmuth B. Variation in the sensitivity of organismal body temperature to climate change over local and geographic scales. Proc Nat Acad Sci U S A. 2006;103:9560-9565.

\section{Publish your work in this journal}

Open Access Animal Physiology is an international, peer-reviewed, open access journal publishing original research, reports, reviews and commentaries on all areas of animal physiology. The manuscript management system is completely online and includes a very

\section{Dovepress}

quick and fair peer-review system. Visit http://www.dovepress.com/ testimonials.php to read real quotes from published authors. 